\title{
AMBULATORY PEDIATRIC ASSOCIATION
}

Program Schedule

Monday, April 27

$$
\text { 2:00 p.m. - 5:00 p.m. Public Policy Committee Avalon A }
$$

Tuesday, April 28

$8: 00$ a.m. - 1:00 p.m.

9:00 a.m. - 4:00 p.m.

$3: 30$ a.m. $-5: 30$ p.m.

\author{
APA Board of Directors' Meeting \\ Teaching the Teachers \\ APA Committee Meetings \\ - Child Health Care Delivery \\ - Education \\ - Research
}

Wednesday, April 29

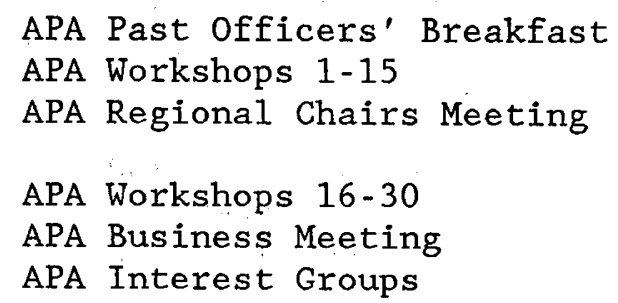
Grant Directors
Avalon A Avalon C

Coronado E Coronado D Coronado $\mathrm{F}$

Santa Cruz See Pocket Pgm. Wrather Board Room See Pocket Pgm. Center Ballroom

Yorba Cerritos Avalon A/B Avalon $\mathrm{C}$ Coronado E Coronado D Sierra Coronado F

\section{Thursday, Apri1 30}

7:30 a.m. - 9:30 a.m.

APA Regional Breakfasts

$$
\begin{aligned}
& \text { - Region I } \\
& \text { - Region II } \\
& \text { - Region III } \\
& \text { - Region IV } \\
& \text { - Region V } \\
& \text { - Region VI } \\
& \text { - Region VII } \\
& \text { - Region VIII } \\
& \text { - Region IX } \\
& \text { - Region X }
\end{aligned}
$$

Avalon A Balboa Avalon B Cerritos Avalon C Coronado D Coronado E Sierra Coronado F Yorba 
Thursday, Apri1 30

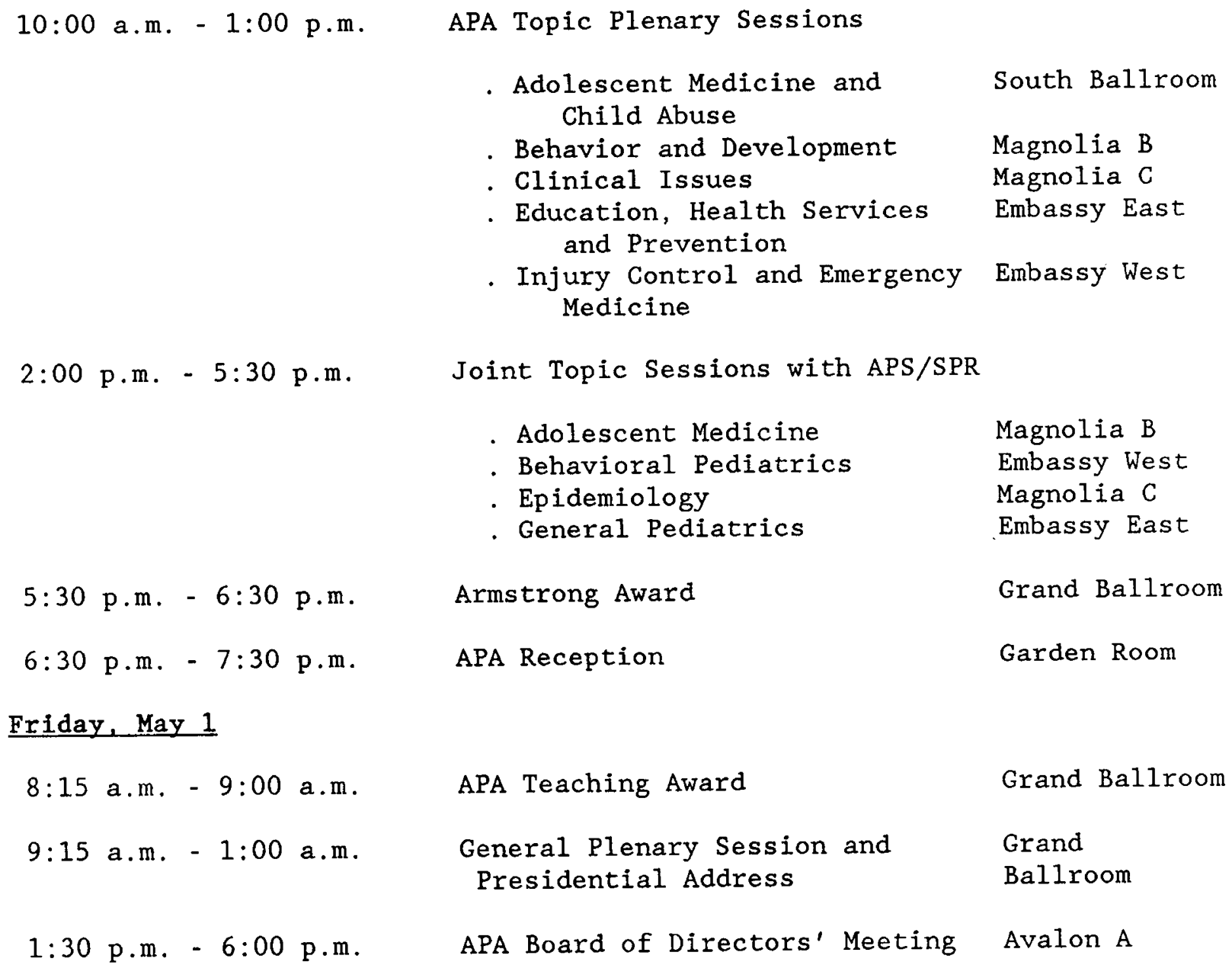

This Meeting is being cosponsored by the American Academy of Pediatrics. This program meets the criteria for $173 / 4$ hours category I of the Physician's Recognition Award of the American Medical Association.

The California State Board of Registered Nursing has approved this program for $173 / 4$ Continuing Education Credits for Registered Nurses. Certificates are available at the APA registration desk. 


\section{AMBULATORY PEDIATRIC ASSOCIATION}

\section{Registration Hours}

\section{Location: Center Lounge, Foyer Registration Area}

\section{Date} Time

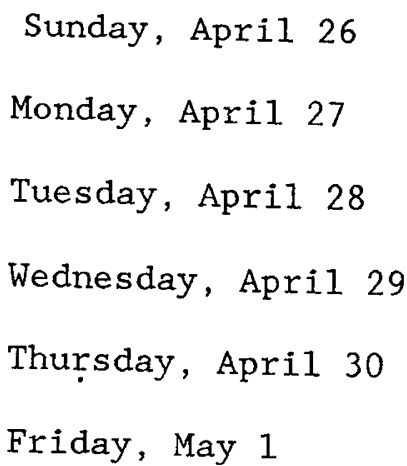

\section{Workshop Registration}

Tuesday, April 28

Wednesday, April 29

$$
\begin{aligned}
& 1: 00 \text { p.m. }-8: 00 \text { p.m. } \\
& \text { 7:30 a.m. - 1:00 p.m. }
\end{aligned}
$$

